TITLE:

\title{
Cognition Enhancing Effect of Rosemary Plant (Rosmarinus officinalis, L) in Preclinical Studies: A Systematic Review and Meta-Analysis
}

Shalam Mohamed Hussain ${ }^{1 *}$, Ayesha Farhana Syeda ${ }^{2}$, Mohammad Alshammari ${ }^{3}$, Sulaiman Alnasser ${ }^{4}$, Naif D. Alenzi ${ }^{5}$, Samyah T. Alanazi ${ }^{6}$, Nandakumar Krishnadas ${ }^{7}$

1 Former faculty and independent researcher, College of Pharmacy, Qassim University, Saudi Arabia

2 Department of Pharmaceutics, Unaizah College of Pharmacy, Qassim University, Saudi Arabia

3 Department of Pharmacy Practice, Unaizah College of Pharmacy, Qassim University, Saudi Arabia

4 Department of Pharmacology, Unaizah College of Pharmacy, Qassim University, Saudi Arabia

5 National Drug and Cosmetic Control Laboratories, Saudi Food and Drug Authority, Riyadh. Saudi Arabia

6 Clinical Laboratory Sciences, College of Applied Medical Sciences, King Saudi University, Riyadh, Saudi Arabia

7 Department of Pharmacology, Manipal College of Pharmaceutical Sciences, Manipal University, India 


\begin{abstract}
Background: Patients with mild cognitive impairment end up progressing to Alzheimer's disease (AD) leading to straining burden on public health. R. officinalis long been known as the herb of remembrance and can be a potential cognition enhancer for AD. The aims of the review were to summarize the qualitative and quantitative aspects of R.O and its active constituents in enhancing the cognition. MATERIALS AND METHOD Google scholar and PubMed structured search to find relevant studies that assessed the effect of R.O extract or any of its active constituents on cognitive performance in animals. Data extraction: Following information from each included study was extracted: (1) article information (2) characteristics of study animals (3) type of intervention; type, dose, duration, and frequency of administration of R.O (4) type of outcome measure. Data synthesis: Data were analyzed using Review Manager (RevMan 5.3, 2014] and metaanalysis was performed for the outcome measures on all relevant tasks within the included papers by computing the standardized mean difference ps. RESULTS. 23 studies for qualitative and fifteen for meta-analysis were selected. From fifteen included papers, 22 studies with 35 comparisons were meta-analyzed. Effect sizes for intact animals and impaired animals respectively was (mean $g$ and 95\% CI 1.19 [0.74, 1.64; 0.57 [0.19,0.96]. The R. officinalis had positive effect on both groups of animals. The subgroup analyses exhibited substantial unexplained heterogeneity between studies. Mechanisms of R.O was anticholinesterase, procholinergic, antioxidant, anti-amyloid, neuroprotective and anti-inflammatory agent CONCLUSIONS: R.O improves cognitive function.
\end{abstract} Limitations: Considerable heterogeneity between studies.

Keywords: Rosemary, Alzheimer's disease, cognition, meta-analysis, preclinical study, mild cognitive dysfunction, herbal drugs, rosmarinic acid 


\section{Introduction}

Mild cognitive impairment often observed in older individuals as a deficit in memory and cognition without any physical limitations in daily activities. This impairment has been found to advance with age and with an increasing older population worldwide, it is further expected increase in the future. A proportion of patients with mild cognitive impairment end up progressing to dementia and Alzheimer's disease (AD) leading to straining burden on public health[1],[2]. Hence it is necessary to delay this progression mild cognitive impairment for which many of the strategies exist, one of which is by the use of cognitive enhancers (also referred as nootropics). Currently, medications approved as cognitive enhancers, especially in the treatment of AD, include cholinesterase inhibitors (e.g., donepezil, rivastigmine and galantamine) and the N-methyl-d-aspartic acid receptor antagonist memantine[3]'[4]. Though they are mainstay of treatment, their efficacy is debatable and come with their own set of adverse effects and limitations. Interest in herbal medications as cognitive-enhancers is increasing with several promising compounds made available for the purpose, like Curcumin, Ginkgo biloba, Bacopa monnieri, Hupericum perforatum, Salvia officinalis (sage), Huperzine A (Lycopodium serratum) and Ginseng[5]-[10]. These herbs have shown promise as cognition enhancers especially in the context of treatment of $\mathrm{AD}$ in terms of their cognitive benefits and more importantly their mechanisms of action that deal with the fundamental pathophysiology of the disease in various preclinical and clinical endeavors.

Rosmarinus officinalis Linn. (R.O, Rosemary) belonging to the family Lamiaceae is an aromatic plant distributed in the Mediterranean region. It is the most popular culinary herbs cultivated all over the world. Its fresh and dried leaves have been used for their characteristic aroma in food cooking or consumed as herbal tea. R.O has been reported for its biological activities such as, antibacterial, anticancer, antidiabetic, anti-inflammatory and antinociceptive, antioxidant], antithrombotic, antiulcerogenic, improving cognitive deficits, antidiuretic and hepatoprotective] effects[11]-[20]. Above all R.O has long been known as the herb of remembrance[21], and occupies a special place in folklore medicine[22].

Pharmacologically active constituents identified in R.O are phenolic diterpenes, triterpenes, and phenolic acids such as carnosic acid (CA), carnosol, rosmanol, ursolic acid, betulinic acid, and rosmarinic acid (RA), nepitrin[23], [24],[25],[12]. Among the isolated phenolic compounds, CA and RA have been shown to possess the most predominant pharmacological effects of R.O and to interact with multiple molecular targets[26], [27],[28],[29][22] (Figure 1). The aims of the present review are to summarize the qualitative and quantitative aspects of the potential benefits of R.O and its active constituents in enhancing the cognition in preclinical studies and to identify the underlying mechanisms of action. 


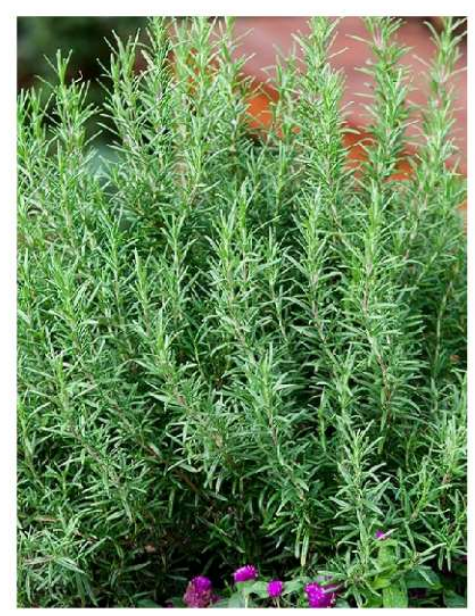<smiles>O=C(C=Cc1ccc(O)c(O)c1)OC(Cc1ccc(O)c(O)c1)C(=O)O</smiles>

Rosemarinic acid<smiles>CC(C)c1cc2c(c(O)c1O)[C@@]1(O)CCCC(C)(C)[C@H]1CC2</smiles>

Carnosic acid

\section{Rosemary officinalis}

Figure 1 Rosemary plant and structures of its chemical constituents

\section{MATERIALS AND METHODS}

\subsection{Literature search strategy}

The present review and meta-analysis were based on published results of animal studies on the effects of R.O on cognitive performance which were identified via Google scholar and PubMed structured search to find relevant studies (last search run on JUNE 2020). In Google scholar text word search of titles and abstracts was conducted using the following search terms: "R.O", "R.O extract", "rodent", "animal", and one of the following: "nootropic", "cognitive enhancing", "cognitive enhancers", "memory enhancing", or "memory enhancement", "memory and learning". For PubMed the following key words (MeSH) for search strategy were used with R.O, rodent and lab studies as the main search concepts; nootropic", "cognitive enhancing", "cognitive enhancers", "memory enhancing", or "memory enhancement", "memory and learning. We also searched reviews to find additional relevant studies. No limits were applied to either date or language of the literatures published.

\subsection{Inclusion and exclusion criteria}

The broad eligibility criteria; with respect to study type, participant types, and outcome measure, were studies that examined the effect of R.O versus a suitable control, healthy intact or cognitively impaired animals as participants, and learning and memory indices of task-performance, respectively. Thus, in conjunction with the above three broad criteria, studies included for the first criteria, if they met the following: (1) Random assignment of animals to groups (2) Animal groups with at least one healthy, intact, control group treated with vehicle and a healthy intact rodent group treated with R.O (3) Use of a recognized test to measure learning and memory response to treatment. With regards to studies included for the second criteria, if they met the following: (1) any dosage of R.O administered for any duration, versus healthy intact control or impaired intact control, (2) Clear 
method of extraction or isolation of active constituent of R.O. Studies included for the third criteria, measurement of duration or speed of performance of learning and memory task by animals. Review articles, case reports, clinical studies, studies involving tasks that focused on other behavioral effects of R.O on rodents were all excluded. The flow of information from identification to inclusion of studies is summarized in figure 2 .

\subsection{Study screening and selection}

Studies that were included in the systematic review and meta-analysis if they fulfilled all of the following criteria: 1) the study assessed the effect of R.O extract or any of its active constituents on cognitive performance 2) the study was performed in animals in vivo; 3) the study was an original full paper which presented unique data. Studies were excluded if 1) if it is clinical study or in vitro study. Titles and abstracts of studies retrieved using the search strategy were screened independently by two review authors to identify studies that potentially met the inclusion criteria outlined above. The full text of these potentially eligible studies was retrieved and independently assessed for eligibility by two review authors. Any disagreement between the two review authors over the eligibility of particular studies was resolved through discussion with a third review author. (figure 2) 


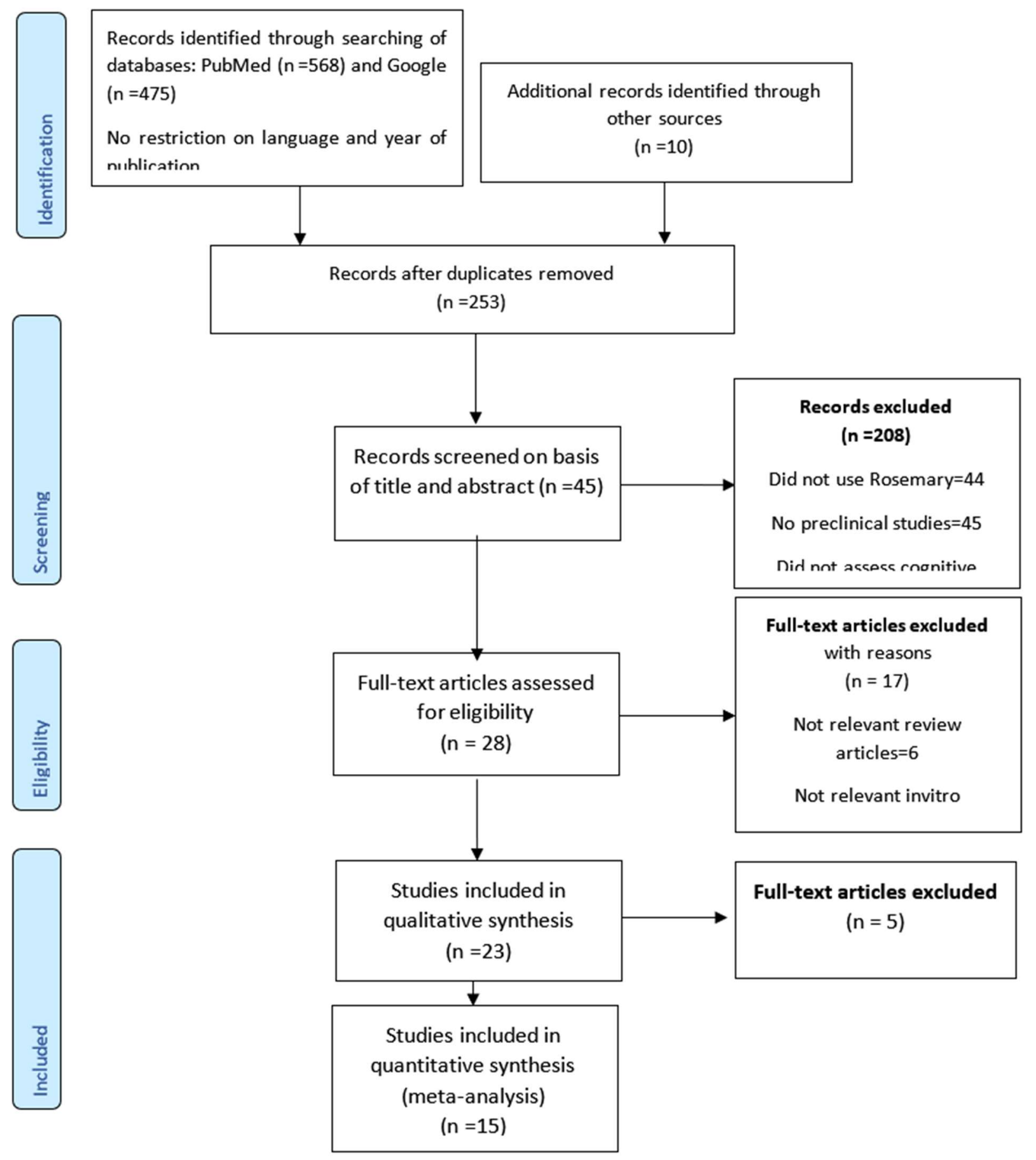

Figure 2. Flow chart of study selection process. The number of studies in each phase is indicated between brackets

\subsection{Data extraction}

We used a data extraction protocol based on the Cochrane Consumers and Communication Review Group's data extraction template. Two authors independently extracted the following information from each included study: (1) article information (author and publication year), (2) characteristics 
of study animals (species, age, weight)(3) type of intervention; type, dose, duration, and frequency of administration of R.O (4) type of outcome measure (task name and all indices of task performance that were used to assess cognition function). The characteristics of the studies extracted are shown in Table 1. Data were extracted if raw data or group averages, standard deviation (SD) or standard error (SE), and number of animals per group (n). If SE was reported, this was converted to SD for meta-analysis. If a study conducted experiments with different tools, the data were extracted separately and treated as independent experiments for moderator analyses and combined to obtain a single effect size (SMD) for the respective study after suitably adjusting its direction of effect with an algorithmic sign. If outcomes were measured at several time points, we used only the results obtained on the day after first acquisition. When data was represented graphically, they were measured using web image analysis software (Web Plot Digitizer 4.2)[30] Eligibility assessment was performed independently in an unblinded standardized manner by two reviewers. Disagreements between reviewers, if any, were resolved by consensus.

\subsection{Quality assessment of the included studies}

We assessed the quality of the included studies based on a 10-point rating system checklist of the Collaborative Approach to Meta-Analysis and Review of Animal Data from Experimental Studies (CAMARADES) applicable to preclinical studies. One point was given for evidence of each quality criterion as included in the table (2). The quality of all studies was assessed independently by two reviewers.

\subsection{Data synthesis and statistical analysis}

Data were analyzed using Review Manager (RevMan 5.3, 2014)[31]. Meta-analysis was performed for the outcome measures (as a continuous outcome variable) on all relevant tasks within the included papers by computing the standardized mean difference (SMD, Hedges, g) of the treatment effect on intact and impaired rodent groups. Each study's effect size, and pooled effect sizes along with their confidence intervals were calculated by weighting with their inverse variance. Random effect models and I-square $\left(\mathrm{I}^{2}\right)$ test were used to assess quantitatively the impact of anticipated study heterogeneity on the results of the meta-analysis. $\mathrm{p}$ value $<.1$ and $\mathrm{I}^{2+}$ value of $>50 \%$ were considered statistically significant. Forest plot was generated to depict the SMD along with its $95 \%$ confidence interval for each study as well as the pooled them. Subgroup analyses were performed to assess the influence of moderators on R.O efficacy, as well as to explore possible causes for heterogeneity. For sub group analyses multiple tasks of a study were entered as independent studies. The moderators used were duration of R.O administration (acute/chronic), type of R.O (whole extract/active constituent), type of memory predominantly assessed (reference memory/recognition memory), species of animal used (rat/mouse) and condition of animal (normal intact/impaired intact). Each of these moderators were individually entered into separate forest plot as a subgroup to assess subgroup interactions. Final forest plot to depict the final effect of R.O on normal intact and impaired intact animals used the SMD along with its 95\% confidence interval for each study (weighted sum of multiple tasks) as well as the pooled mean difference by combining all studies. In studies where multiple tasks were conducted, the weight score was divided by the number of tasks within a study.

\subsection{Sensitivity analysis}

Sensitivity analysis showed that no single individual study had any significant impact on the overall results. 


\subsection{Qualitative synthesis of data for Cognitive-Enhancing effects of R.O and its active compounds}

All the included papers for quantitative study and other relevant studies were reviewed to gather collective data on various extracts, active constituents of R.O and their effects in improving cognitive performance in preclinical studies.

Nasiara Karim, et al [25] isolated nepitrin from R.O (dose levels of 50, 100 and $200 \mathrm{mg} / \mathrm{kg}$, PO 60 min before the tests) to investigate its antiamnesic effect in Swiss male albino mice in Y-maze and NORT tests. In Y-Maze test it produced a significant $(p<0.01)$ dose dependent decrease in the same arm entries and corresponding increase in alternations. Similarly, in NORT nepitrin treated mice spent a longer time investigating novel object indicating an increased discriminatory between new and familiar objects. In in vitro studies nepitrin showed a concentration dependent anticholinesterase and antioxidant activities.

Marcin Ozarowski, et al[32] used ethanolic extract of leaves of R.O (at a dose of $200 \mathrm{mg} / \mathrm{kg}$ ) and isolated rosmarinic acid (RA, $10 \mathrm{mg} / \mathrm{KG}$ ) on male six-week-old Wistar rats using passive avoidance(PA) and NORT tests where they produced no significant effect but overcame the effects of pretreated scopolamine. In isolated brain regions of treated animals, RE and RA showed inhibition of $\mathrm{AChE}$ and enhancement of BuChE activities in the frontal cortex and hippocampus.

Hai Song, et al [33] et al performed the experiments using commercial extracts of RO containing $20 \%$ carnosic acid (at 40, 80 and $160 \mathrm{mg} / \mathrm{kg}$ ) on mild traumatic brain injury (mTBI) induced adult male Sprague-Dawley rats where extract was administered PO for 16 days during training and testing for 1-7 days post injury. In Morris water maze (MWM), treatment restored the spatial learning and memory deficits induced by rmTBI. Tissue analysis also revealed that the RO treatment reduced the rmTB induced degeneration of neurons, astrocytosis, oxidative stress, inflammatory cytokines in hippocampus.

Anastasia-V. Ferlem, et al [34] used the infusion of RO leaves (administered 2\% w/v/day for 4 weeks) to adult male old Balb-c mice using PA test, where the RO administration did not produce any significant changes in latency time. However, tissue analysis of brain and liver showed significantly decreased AChE activity.

Camila Angela Zanella, et al [35] used hydroalcoholic extract of RO (at doses of $10 \mathrm{mg} / \mathrm{kg}, 150$ $\mathrm{mg} / \mathrm{kg}$ and $300 \mathrm{mg} / \mathrm{kg}$ ) in adult Swiss male mice and performed experiments using social recognition (SR), MWM and PA tasks. The treatment with 150 and $300 \mathrm{mg} / \mathrm{kg}$ of RO improved the acquisition phase of learning in SR but in MWM, no significant effect was observed. However, in PA, RO at $150 \mathrm{mg} / \mathrm{kg}$ improved long-term memory in the consolidation phase of learning.

Homa Rasoolijazi, et al [36] used RO extract (containing 40\% carnosic acid) at doses of 50,100 and $200 \mathrm{mg} / \mathrm{kg} /$ day, PO for a period of 12 weeks in adult male Wistar rats using MWM. RO at $100 \mathrm{mg} / \mathrm{kg}$ significantly $(\mathrm{p}<0.05)$ improved spatial memory and isolated brain tissue analysis revealed a significantly increased activity of antioxidant enzymes in the hippocampus.

Susan A. Farr et al[37] evaluated effects of two extracts, RO and spearmint extract containing carnosic acid and rosmarinic acid, respectively using specially inbred SAMP8 mice model of accelerated aging. Further, two RO extracts, contained carnosic acid (CA 60\% or CA 10\%) and one spearmint extract contained 5\% RA. Three dose levels of each were selected $(32,16,1.6 \mathrm{mg} / \mathrm{kg})$. Following treatment for 90 days, the mice were tested in 3 different instruments: T-maze foot shock 
avoidance, NORT and lever press tests. All the extracts showed varied response in these tests including, RO with 60\% CA improved acquisition and retention in all the three tests whereas RO with 10\% CA improved only acquisition. On the other hand, spearment extract with 5\% RA improved both acquisition and retention in T-maze foot shock avoidance and lever press tests respectively. In brain tissue analysis all the extracts reduced the 4-hydroxynonenal (HNE) in the cortex significantly. There was also a significant reduction in protein carbonyls in the hippocampus by both RO with 10\% CA and spearmint extract with 5\% RA.

H. Rasoolijazi, et al [38] et al injected A $\beta(1-40)$ by stereotaxic surgery into the Cal region of the hippocampus of rats and administration of CA $(10 \mathrm{mg} / \mathrm{kg}$, IP) was done before and after surgery. PA and Y-Maze tests were conducted to observe the effect of $\beta A$ on $C A$ treatment on learning and memory behavior. $\mathrm{CA}$ prevented the $\mathrm{A} \beta$ induced deficiencies in stepdown latency and spontaneous alternation behavior scores in the PA and Y-maze respectively. Tissue analysis also revealed that $\mathrm{CA}$ reduced the degenerating hippocampal neurons.

H Hosseinzadeh, et al [39] studied the effect of essential oil of RO on male Wistar rats MWM test was used to assess the effects on scopolamine-induced learning deficits and normal rats where administration of essential oil at doses of $125-250 \mathrm{mg} / \mathrm{kg}$ for 5 consecutive days decreased the latency time to find the platform in both normal and scopolamine induced rats.

Luminita Capatina, et al [40] studied the effect of RO essential oil (REO: 25, 150, and $300 \mu \mathrm{L} / \mathrm{L}$ ) in fish, administered by immersion to scopolamine-induced deficient zebrafish once daily for eight days. The test used was a modified Y-Maze for zebra fish where treated fish showed increased time spent in novel arm of the Y-Maze indicating a cognitive-enhancing action and abolished the scopolamine induced AChE alteration in brain autopsy when compared to untreated control fish.

Ah Young Lee, et al [41] investigated effect of RA $(0.25 \mathrm{mg} / \mathrm{kg} /$ day, PO) for 14 days in A $\beta 25-35$ induced deficits in male ICR mice using T-maze, NORT and MWA tests. The RA significantly enhanced alternation movements, object discrimination and decreased latency to reach the platform in the T-maze, NORT and MWM tests, respectively. Furthermore, RA significantly decreased the levels of nitric oxide (NO) and malondialdehyde (MDA) in the brain, kidney, and liver indicating a cognitive improvement

Parisa Hasanein, et al,[42] studied effect of RA in streptozocin-induced diabetic and non-diabetic adult male Wistar rats. Diabetes induced deficits in acquisition and retrieval processes were examined after 30 days of treatment with RA using PA test where, it showed increased stepdown latency (enhanced cognition). The treatment also enhanced antioxidant enzymes superoxide dismutase and catalase in blood.

Tursun Alkam, et al,[43] A $\beta 25-35$ induced male ICR mice were treated with RA $(0.05,0.25,1,2$, and $4 \mathrm{mg} / \mathrm{kg}$ day, i.p.) for 14 days and tested using Y maze and NORT tasks where increased spontaneous alternation behavior and increased novel discriminatory exploration was observed, respectively. In in vitro studies, RA, prevented A25-35-induced nitration of proteins, indicating a scavenging of ONOO effect. Thus, demonstrating the protective and memory enhancing effect of RA.

Dong Hyun Park, et al [44]demonstrated the ability of RA in adult male ICR mice to enhance cognitive effect in MWM test following acute and sub chronic treatment. It also caused inhibition of prolyl oligopeptidase (POP) in brain. 
Patricia Pereira, et al[29] used adult Wistar rats to investigate effect of RA (1, 2, 4 or $8 \mathrm{mg} / \mathrm{kg}$, IP) using PA apparatus where RA ( 2 and $4 \mathrm{mg} / \mathrm{kg}$ ) showed a significant increase in step-down latency. The brain images of treated rats showed no significant DNA damage by RA.

Kunio KOSAKA and Toshio YOKOI[28] carried out the extraction of dried leaves of RO to prepare aqueous and alcoholic extracts. Further from the alcoholic extracted they isolated CA and carnosol through column chromatography. They were all tested on T98G human glioblastoma cells where enhanced production of nerve growth factor (NGF) was found. However, CA was the most efficient and effective among them.

Ilkay Orhan et al[45] prepared various extracts and essential oil of Turkish RO and tested for AChE and $\mathrm{BChE}$ inhibitory activities. Among them essential oil produced quite notable inhibitions of both $\mathrm{AChE}$ and $\mathrm{BChE}$, and other extracts did not produce significant inhibition. However, RA, from methanolic extract of RO showed a remarkable BChE-inhibitory effect.

Sanda Vladimir-Knežević, et al[46]carried the comparative study of AChE inhibitory and antioxidant activities of a large number of lamiaceae medicinal plants containing RA, including R.O where many extracts eexhibited a strong inhibitory effect for AChE indicating a prominent role of RA in this effect. All the tested extracts also demonstrated moderate to strong antioxidant activities.

Tomoki Hase, et al[47] proposed a new mechanism for the inhibition of A $\beta$ aggregation by RA polyphenols and monoamines is via an o-quinone structure which specifically binds to $A \beta$ and prevents further aggregation. DA in its oxidation state transforms to o-quinone structure and thereby interfering $A \beta$ aggregation. RA, suppresses $A \beta$ accumulation in mice brain by increasing concentration of monoamine including DA.

Alberto Cornej, et al [48] demonstrated RA the most active compound that inhibited tau fibrillization. and prevents b-sheet assembly.

Abdelfattah El Omri, et al [49], carried tests in PC12 cells where various extracts and fractions of R.O showed a dose dependent increase in AChE activity. CA and RA-induced PC12 cells differentiation, improved total choline level and ACh synthesis in PC12 cells. Also showed neurotrophic effects in PC12 cells leading to attenuated cholinergic neurons atrophy resulting in an enhancement of memory, attention and impaired behavior.

\section{RESULTS}

\subsection{Study selection}

The electronic search strategy retrieved from PubMed $(n=568)$, Google Scholar $(n=475)$ records and other sources $(n=10)$. From this 253 were left after removing duplicates. Following screening of title and abstracts $(n=45)$ were retained for full text article assessment. Twenty-eight papers met our inclusion criteria. Further, twenty-three investigating the cognitive effect of R.O on animal models were included in the qualitative analysis and finally fifteen studies were selected for the quantitative analysis (meta-analysis) $24,28,38-42$

\subsection{Study characteristics}

The characteristics of the included studies are summarized in Table 1. There was a large variation in the characteristics of selected studies with respect to study design, animal models, outcome measures and study animals. They were all conducted between 2004 to 2020 in different parts of the 
world. There were fifteen included papers with 22 studies for quantitative analysis. They had in total 35 comparisons; one study was performed with zebra fish as study animal 11 studies used rats and 10 studies were performed on mice. There were nearly 488 study animals as participants, 232 rats, 236 mice and 20 zebra fish. Among the studies, 13 had normal intact animals and 9 had impaired intact animals. Out of 15 papers, three papers reported only intact animals that were cognitively impaired by chemical or physical means, 6 papers reported normal, intact animals. However, 6 reported both cognitively impaired intact animals and normal intact animals. There were 298 normal intact animals and 190 that were cognitively impaired. The common method used to induce impairment in the cognition of the animals was scopolamine (5), Aßprotein (3), brain injury (1) and STZ (1). All were published in the English language except one which was published in Persian (abstract available in English) and was translated. The duration of administration of R.O ranged from half an hour (4) before experiment to one week (3) to several weeks (8) before experimenting. The common form of the R.O used in the experiments was whole extract (6), any of the active constituents (8) of the plant of R.O and some studies employed both (1). The active constituents that were explored in these studies were, rosmarinic acid (6), carnosic acid (2) and nepitrin (1). The common route of administration used for administration of R.O was oral (10), intraperitoneal (4) and by immersion (1). All the included studies assessed change in cognitive performance between control and treated groups as an index of cognitive function. For measuring the cognitive function, different tests and tools were used including morris water maze (5), passive and active avoidance paradigms (6), T and Y mazes (6) and social (1) and novel object recognition tests (4). The type of memory that was assessed by these studies using different experimental tools (35) were reference memory (26) and recognition memory (9). Nearly half of the studies performed multiple tasks (6) to assess cognitive functions. The common index used to assess outcome of performance was latency to reach a target or escape an aversive stimulus, time spent in target area and time spent investigating a novel object (Table 1).

\subsection{Methodological quality of studies}

As shown in the Table 2, the score of the included studies quality ranged from 7 to 9 of a total possible 10 points. Majority of the studies reported the randomization of animals into treatment groups, but did not mention the method of randomization. All studies were published in peer reviewed journals and stated the potential conflict of interests or funding sources. However, none of the studies reported blinded assessment of outcome measures and none of the studies described any method to calculate sample size.

\subsection{Meta-analysis}

Results for the outcome measure cognitive performance are summarized in table 3 and figure 3 . The Random effect models with IV was adopted to generate forest plots of effect sizes with Hedges, $g$ test. Hedges g was used due to the expected heterogenous nature of preclinical studies and to account for the anticipated biases. The analysis included the data for 248 intact control animals and 280 animals that underwent treatment with R.O (maximal dose only). Figure 3 illustrates the effect size (SMD, Hedges, g) and 95\% confidence interval for each of the 22 comparisons from 15 selected studies. Across studies, there was a large positive effect of $R$. $O$ for intact rodents' performance (mean $g$ and $95 \%$ CI $1.19[0.74,1.64])$ which was statistically significant $(Z=5.21, P<0.00001)$, indicating a considerably enhanced memory processes among intact rodents due to administration of R.O. A visual assessment of the studies' results suggests between-study variability and the majority of individual study point estimates of the treatment effect are on the same side of the line of null effect 
but do not overlap, indicating a difference in treatment effect magnitude among studies. The confidence intervals for each study's treatment effect (horizontal lines) overlap one another, but the upper and lower limits of the CI do not consistently line up on a vertical axis, indicating differences in estimation of the population treatment effect among studies. Thus, suggesting the presence of significant heterogeneity $\left(\mathrm{Chi}^{2}=91.40, \mathrm{df}=21, \mathrm{P}=000001, \mathrm{I}^{2}=77 \%\right)$. Figure 4 and 5 represent the forest plots of effect sizes for the R.O effect on normal intact and cognitively impaired animals respectively. Figure 4 shows the results for 12 studies that included the data for 125 intact control animals and 141 animals that underwent treatment with R.O (maximal dose only). The overall estimate displays a positive effect of $R$. $O$ for normal intact animals' performance (mean $g$ and $95 \%$ CI $0.57[0.19,0.96]$ which was statistically significant $(Z=2.91, P<0.004)$. Similarly, figure 5 shows the results for 10 studies that included the data for 103 intact impaired animals and 119 impaired animals that underwent treatment with R.O (maximal dose only). However, the overall estimate for the treated impaired intact animals was stronger (mean $g$ and 95\% CI 1.93 [1.14,2.72], Z=4.79 (P< $0.0001)$ than the normal intact treated ones. 
Table 1. Preclinical studies examining the effect of $R$. officinalis on cognitive performance of healthy and impaired intact animals

\begin{tabular}{|c|c|c|c|c|c|c|c|}
\hline Author, year & $\begin{array}{l}\text { R. officinalis type: } \\
\text { maximal dose X } \\
\text { Duration X Route. } \\
\text { admin }\end{array}$ & $\begin{array}{l}\text { Animal } \\
\text { species/age/weig } \\
\text { ht(gms) }\end{array}$ & Task(s) & $\begin{array}{l}\text { No. of } \\
\text { healthy } \\
\text { animals } \\
\text { (max dose) }\end{array}$ & $\begin{array}{l}\text { Impairment } \\
\text { method }\end{array}$ & $\begin{array}{l}\text { No. of } \\
\text { impaired } \\
\text { animals } \\
\text { (max dose) }\end{array}$ & $\begin{array}{l}\text { Outcome } \\
\text { Index }\end{array}$ \\
\hline Farr, 2016 & CA:32mg/kgX16wXPO & Mice $/ 9 \mathrm{~m} / 30-40 \mathrm{~g}$ & $\begin{array}{l}\text { T-Maze } \\
\text { NORT }\end{array}$ & 48 & --- & - & $\begin{array}{l}\text { Escape latency, } \\
\text { discriminatory } \\
\text { recognition }\end{array}$ \\
\hline Ferlemi, 2015 & RE:2\%InfusionX4wXPO & $\begin{array}{l}\text { Mice } / 3-4 \mathrm{~m} / 30- \\
40 \mathrm{~g}\end{array}$ & $\begin{array}{l}\text { Passive } \\
\text { avoidance }\end{array}$ & 16 & - & - & $\begin{array}{l}\text { Stepdown } \\
\text { latency }\end{array}$ \\
\hline Hai Song, 2016 & RE:10mg/kg/7d X PO & $\begin{array}{l}\text { Wistar } \\
\text { rats } / 6 \mathrm{w} / 270- \\
300 \mathrm{~g}\end{array}$ & MWM & 24 & $\begin{array}{l}\text { Mild brain } \\
\text { injury }\end{array}$ & 24 & $\begin{array}{l}\text { Latency to } \\
\text { platform and } \\
\text { time spent }\end{array}$ \\
\hline $\begin{array}{l}\text { Hosseinzade, } \\
2004\end{array}$ & RE: $500 \mathrm{mg} / \mathrm{kgX} 6 \mathrm{dXPO}$ & $\begin{array}{l}\text { Wistar rats/adult/ } \\
250-300 \mathrm{~g}\end{array}$ & MWM & 12 & Scopolamine & 12 & $\begin{array}{l}\text { Latency to } \\
\text { platform }\end{array}$ \\
\hline $\begin{array}{l}\text { Ozarowski, } \\
2013\end{array}$ & $\begin{array}{l}\text { RE: } 200 \mathrm{mg} / \mathrm{kg} / 28 \mathrm{dXPO} \\
\mathrm{RA}: 10 \mathrm{mg} / \mathrm{kg} / 28 \mathrm{dXPO}\end{array}$ & Wistar rats $/ 5 \mathrm{w}$ & $\begin{array}{l}\text { Passive } \\
\text { avoidance } \\
\text { NORT }\end{array}$ & 48 & Scopolamine & 48 & $\begin{array}{l}\text { Stepdown } \\
\text { latency, } \\
\text { discriminatory } \\
\text { recognition }\end{array}$ \\
\hline $\begin{array}{l}\text { Rasoolijazi, } \\
2013\end{array}$ & CA: $10 \mathrm{mg} / \mathrm{kgX} 12 \mathrm{dXIP}$ & $\begin{array}{l}\text { Wistar rats/240- } \\
280 \mathrm{~g}\end{array}$ & $\begin{array}{l}\text { Passive } \\
\text { avoidance } \\
\text { Y-Maze }\end{array}$ & 28 & Amyloid $\beta$ & 28 & $\begin{array}{l}\text { Stepdown } \\
\text { latency, } \\
\text { alternation } \\
\text { behavior }\end{array}$ \\
\hline $\begin{array}{l}\text { Rasoolijazi, } \\
2014\end{array}$ & RE:200mg/kgX12wXPO & $\begin{array}{l}\text { Wistar rats } / 9 \mathrm{~m} / \\
250-330 \mathrm{~g}\end{array}$ & MWM & 16 & - & - & $\begin{array}{l}\text { Latency to } \\
\text { platform and } \\
\text { time spent } \\
\end{array}$ \\
\hline Zanella, 2012 & $\begin{array}{l}\mathrm{RE}: 300 \mathrm{mg} / \mathrm{kgX} 30 \mathrm{~min} \mathrm{XP} \\
\mathrm{O}\end{array}$ & $\begin{array}{l}\text { Swiss } \\
\text { mice } / 8 \mathrm{w} / 35 \mathrm{~g}\end{array}$ & $\begin{array}{l}\text { Social } \\
\text { recognition } \\
\text { MWM } \\
\text { Inhibitory } \\
\text { Avoidance } \\
\end{array}$ & 36 & - & - & $\begin{array}{l}\text { Social } \\
\text { investigation } \\
\text { time, time } \\
\text { spent on } \\
\text { platform, }\end{array}$ \\
\hline
\end{tabular}




\begin{tabular}{|c|c|c|c|c|c|c|c|}
\hline & & & & & & & $\begin{array}{l}\text { Stepdown } \\
\text { latency }\end{array}$ \\
\hline Karima, 2017 & $\begin{array}{l}\text { Nepitrin:200mg/kg/X1h } \\
\text { XPO }\end{array}$ & $\begin{array}{l}\text { Swiss mice/20- } \\
30 \mathrm{~g}\end{array}$ & $\begin{array}{l}\text { Y-Maze } \\
\text { NORT }\end{array}$ & - & Scopolamine & 24 & $\begin{array}{l}\text { alternation } \\
\text { behavior, } \\
\text { discriminatory } \\
\text { recognition }\end{array}$ \\
\hline Capatina,2020 & $\mathrm{RE}: 300 \mu \mathrm{l} / 1 \mathrm{X} 8 \mathrm{~d}$ & $\begin{array}{l}\text { Zebra fish/adult / } \\
\text { 3-4-m }\end{array}$ & Y-MAZE & - & Scopolamine & 20 & $\begin{array}{l}\text { Time spent in } \\
\text { novel arm }\end{array}$ \\
\hline Lee, 2016 & $\begin{array}{l}\text { RA: } 0.25 \mathrm{mg} / \mathrm{kgX} 14 \\
\text { dXPO }\end{array}$ & ICR mice $/ 5 \mathrm{w}$ & T-MAZE & - & Amyloid $\beta$ & 16 & $\begin{array}{l}\text { alternation } \\
\text { behavior }\end{array}$ \\
\hline Hasanein,2016 & RA: $30 \mathrm{mg} / \mathrm{kg} / 30 \mathrm{dXIP}$ & $\begin{array}{l}\text { Wistar rats } / 3-4 \\
\mathrm{~m} / 250-280 \mathrm{~g}\end{array}$ & $\begin{array}{l}\text { Passive } \\
\text { avoidance }\end{array}$ & 14 & STZ & 14 & $\begin{array}{l}\text { Stepdown } \\
\text { latency }\end{array}$ \\
\hline Alkama, 2007 & RA: $4 \mathrm{mg} / \mathrm{kg} / 9 \mathrm{~d}$ X IP & Male ICR mice & $\begin{array}{l}\text { Y-maze } \\
\text { test } \\
\text { NORT }\end{array}$ & 20 & Amyloid $\beta$ & 20 & $\begin{array}{l}\text { alternation } \\
\text { behavior, } \\
\text { discriminatory } \\
\text { recognition }\end{array}$ \\
\hline Park, 2010 & RA:8mg/KG/3Wx PO & $\begin{array}{l}\text { ICR mice/25-30 } \\
\mathrm{g}\end{array}$ & MWM & 12 & - & - & time spent \\
\hline Pereira,2005 & RA: $8 \mathrm{mg} / \mathrm{kg} / 30 \mathrm{~min}$ X IP & $\begin{array}{l}\text { Wistar rats/2- } \\
3 \mathrm{~m} /\end{array}$ & $\begin{array}{l}\text { Passive } \\
\text { avoidance }\end{array}$ & 16 & - & - & Stepdown \\
\hline
\end{tabular}

CA: Carnosic acid, RA: Rosmarinic acid, RE: Rosemary Extract of any plant part 
Table 2: Quality assessment of the included studies

\begin{tabular}{|c|c|c|c|c|c|c|c|c|c|c|c|c|c|c|c|c|}
\hline S. No & Study References & 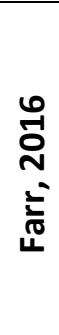 & 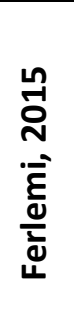 & 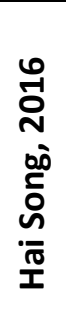 & 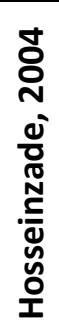 & 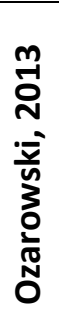 & 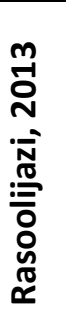 & 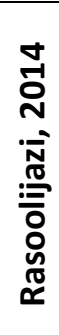 & 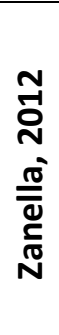 & 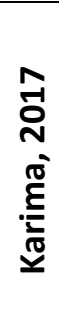 & 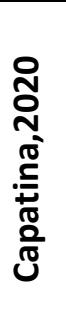 & 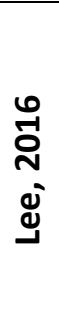 & 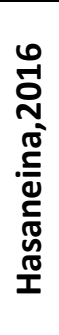 & 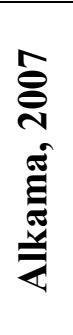 & 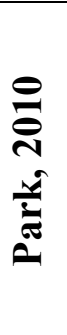 & 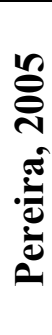 \\
\hline 1 & $\begin{array}{l}\text { Publication in a peer-reviewed } \\
\text { journal }\end{array}$ & $\sqrt{ }$ & $\mathrm{V}$ & $\mathrm{V}$ & $\mathrm{V}$ & $\mathrm{V}$ & $\mathrm{V}$ & $\mathrm{V}$ & $\mathrm{V}$ & $\mathrm{V}$ & $\mathrm{V}$ & $\mathrm{V}$ & $\mathrm{V}$ & $\mathrm{V}$ & $\mathrm{V}$ & $\mathrm{V}$ \\
\hline 2 & $\begin{array}{l}\text { Research question specified and } \\
\text { clear? }\end{array}$ & $\mathrm{V}$ & $\mathrm{V}$ & $\mathrm{v}$ & $\mathrm{V}$ & $\mathrm{V}$ & $\mathrm{V}$ & $\mathrm{V}$ & $\mathrm{V}$ & $v$ & $v$ & $\mathrm{~V}$ & $\mathrm{~V}$ & $v$ & $v$ & $v$ \\
\hline 3 & $\begin{array}{l}\text { Animal husbandry conditions } \\
\text { specified }\end{array}$ & $\sqrt{ }$ & $\mathrm{V}$ & $\mathrm{V}$ & $\mathrm{V}$ & $\mathrm{V}$ & $\mathrm{V}$ & $\mathrm{V}$ & $\mathrm{V}$ & $\mathrm{V}$ & $\mathrm{V}$ & $\mathrm{V}$ & $\mathrm{V}$ & $\mathrm{V}$ & $\mathrm{V}$ & $\mathrm{V}$ \\
\hline 4 & $\begin{array}{l}\text { Outcome assessment randomized } \\
\text { across groups? }\end{array}$ & $\sqrt{ }$ & $\mathrm{V}$ & $\mathrm{V}$ & $\mathrm{V}$ & $\mathrm{V}$ & $\sqrt{ }$ & $\mathrm{V}$ & $\mathrm{V}$ & $\sqrt{ }$ & $\mathrm{V}$ & $\sqrt{ }$ & $\mathrm{V}$ & $\mathrm{V}$ & $\mathrm{V}$ & $\sqrt{ }$ \\
\hline \multirow[t]{6}{*}{5} & $\begin{array}{l}\text { Group characteristics clearly } \\
\text { described?* }\end{array}$ & & & & & & & & & & & & & & & \\
\hline & Number of animals per group & $\sqrt{ }$ & $\sqrt{ }$ & $\mathrm{V}$ & $\sqrt{ }$ & $\sqrt{ }$ & $\mathrm{V}$ & 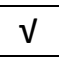 & $\sqrt{ }$ & $\sqrt{ }$ & $\mathrm{V}$ & $\mathrm{V}$ & $\mathrm{V}$ & $\mathrm{V}$ & $\sqrt{ }$ & $\sqrt{ }$ \\
\hline & Species & $\sqrt{ }$ & $\mathrm{V}$ & $\sqrt{ }$ & $\sqrt{ }$ & $\sqrt{ }$ & $\mathrm{V}$ & $\sqrt{ }$ & $\mathrm{V}$ & $\sqrt{ }$ & $\sqrt{ }$ & $\sqrt{ }$ & $\mathrm{V}$ & $\sqrt{ }$ & $\mathrm{V}$ & $\sqrt{ }$ \\
\hline & Weight & $\sqrt{ }$ & $\sqrt{ }$ & $\sqrt{ }$ & $\sqrt{ }$ & $\sqrt{ }$ & $\sqrt{ }$ & $\sqrt{ }$ & $\mathrm{V}$ & $\sqrt{ }$ & $\sqrt{ }$ & $\mathrm{V}$ & $\mathrm{V}$ & $\mathrm{V}$ & $\mathrm{V}$ & $\sqrt{ }$ \\
\hline & Age & $\mathrm{V}$ & $\mathrm{V}$ & $\sqrt{ }$ & $\sqrt{ }$ & $\sqrt{ }$ & $\mathrm{V}$ & $\sqrt{ }$ & $\mathrm{V}$ & $\sqrt{ }$ & $\mathrm{V}$ & $\sqrt{ }$ & $\mathrm{V}$ & $\sqrt{ }$ & $\mathrm{V}$ & $\sqrt{ }$ \\
\hline & Animals randomized across groups & $\sqrt{ }$ & $\sqrt{ }$ & $\mathrm{V}$ & $\sqrt{ }$ & $\sqrt{ }$ & $\sqrt{ }$ & $\sqrt{ }$ & $\mathrm{V}$ & $\sqrt{ }$ & $\sqrt{ }$ & $\sqrt{ }$ & $\mathrm{V}$ & $\sqrt{ }$ & $\sqrt{ }$ & $\mathrm{V}$ \\
\hline 6 & $\begin{array}{l}\text { Time of outcome measurement } \\
\text { clearly described? }\end{array}$ & $\sqrt{ }$ & $\sqrt{ }$ & $\mathrm{v}$ & $\mathrm{V}$ & $\sqrt{ }$ & $\sqrt{ }$ & $\sqrt{ }$ & $\mathrm{v}$ & $\sqrt{ }$ & $\sqrt{ }$ & $\sqrt{ }$ & $\sqrt{ }$ & $\sqrt{ }$ & $\mathrm{v}$ & $\mathrm{v}$ \\
\hline 7 & $\begin{array}{l}\text { Blinded assessment of outcome } \\
\text { measure }\end{array}$ & $x$ & $\sqrt{ }$ & $\mathrm{v}$ & $x$ & $\sqrt{ }$ & $\sqrt{ }$ & $\mathrm{x}$ & $\mathrm{x}$ & $x$ & $\mathrm{x}$ & $x$ & $\mathrm{X}$ & $x$ & $\mathrm{X}$ & $x$ \\
\hline 8 & $\begin{array}{l}\text { Route of administration was } \\
\text { specified }\end{array}$ & v & V & $\mathrm{V}$ & $\mathrm{V}$ & $\mathrm{V}$ & $\mathrm{V}$ & $\mathrm{V}$ & $\mathrm{V}$ & $\mathrm{V}$ & $\mathrm{V}$ & $v$ & $\mathrm{v}$ & $\mathrm{V}$ & $\mathrm{v}$ & $\mathrm{V}$ \\
\hline 9 & $\begin{array}{l}\text { Sample size or dose calculation } \\
\text { formula used }\end{array}$ & $x$ & $x$ & $x$ & $x$ & $x$ & $x$ & $x$ & $x$ & $x$ & $x$ & $x$ & $x$ & $x$ & $x$ & $x$ \\
\hline
\end{tabular}




\begin{tabular}{|c|l|l|l|l|l|l|l|l|l|l|l|l|l|l|l|l|}
\hline 10 & $\begin{array}{l}\text { Described the used experimental } \\
\text { tools/ instruments/animal } \\
\text { models/drug? }\end{array}$ & $\sqrt{ }$ & $\mathrm{x}$ & $\mathrm{V}$ & $\mathrm{X}$ & $\mathrm{V}$ & $\mathrm{V}$ & $\mathrm{V}$ & $\mathrm{V}$ & $\mathrm{V}$ & $\mathrm{V}$ & $\mathrm{V}$ & $\mathrm{V}$ & $\mathrm{V}$ & $\mathrm{V}$ & $\mathrm{V}$ \\
\hline & Total score & $\mathbf{8}$ & $\mathbf{8}$ & $\mathbf{9}$ & $\mathbf{7}$ & $\mathbf{9}$ & $\mathbf{9}$ & $\mathbf{8}$ & 8 & 8 & 8 & 8 & 8 & 8 & 8 & 8 \\
\hline & Maximal Possible score & 10 & 10 & 10 & 10 & 10 & 10 & 10 & 10 & 10 & 10 & 10 & 10 & 10 & 10 & 10 \\
\hline & Quality (\%) & $\mathbf{8 0}$ & $\mathbf{8 0}$ & $\mathbf{9 0}$ & $\mathbf{7 0}$ & $\mathbf{9 0}$ & $\mathbf{9 0}$ & $\mathbf{8 0}$ & $\mathbf{8 0}$ & $\mathbf{8 0}$ & $\mathbf{8 0}$ & $\mathbf{8 0}$ & $\mathbf{8 0}$ & $\mathbf{8 0}$ & $\mathbf{8 0}$ & $\mathbf{8 0}$ \\
\hline
\end{tabular}

$V=$ fulfilling the criterion, $X=$ not fulfilling the criterion. * required to satisfy all to get score (a:\# per group, b:species, C:weight, d:randomized across groups) of the study Population 
Table 3: Comparison of group estimates (Hedges g) with $95 \% \mathrm{Cl}$ with their overall effect (Std. Mean Difference (SMD), IV, Random Effect)

\begin{tabular}{|c|c|c|c|c|c|}
\hline S.No. & Subgroup & Studies & Participants & Effect Estimate & $\begin{array}{l}\text { Overall effect } \\
\mathrm{Z} \text { value(p) }\end{array}$ \\
\hline \multirow[t]{3}{*}{1} & Animal condition & 22 & 488 & $1.19[0.74,1.64]$ & $5.21(\mathrm{P}<0.00001)$ \\
\hline & 2.1.1 INTACT & 12 & 266 & $0.57[0.19,0.96]$ & $2.91(0.004)$ \\
\hline & 2.1.2 IMPAIRED & 10 & 222 & $1.93[1.14,2.72]$ & $4.79(\mathrm{P}<0.0001)$ \\
\hline \multirow[t]{3}{*}{2} & Animal species & $21 \#$ & $468 \#$ & $1.14[0.69,1.60]$ & $4.93(\mathrm{P}<0.00001)$ \\
\hline & 2.1.1 RAT & 11 & 232 & $0.80[0.25,1.34]$ & $2.88(\mathrm{P}=0.004)$ \\
\hline & 2.1.2 MOUSE & 10 & 236 & $1.58[0.81,2.35]$ & $4.02(\mathrm{P}<0.0001)$ \\
\hline \multirow[t]{3}{*}{3} & Type of drug & 22 & 488 & $1.19[0.74,1.64]$ & $5.21(\mathrm{P}<0.00001)$ \\
\hline & 2.1.1 Extract & 10 & 240 & $0.61[0.25,0.96]$ & $3.36(\mathrm{P}=0.0008)$ \\
\hline & 2.1.2 Active & 12 & 248 & $1.86[1.05,2.67]$ & $4.51(\mathrm{P}<0.00001)$ \\
\hline \multirow[t]{3}{*}{4} & Duration of treatment & 22 & 488 & $1.19[0.74,1.64]$ & $5.21(\mathrm{P}<0.00001)$ \\
\hline & 2.1.1 ACUTE & 4 & 76 & $1.35[-0.24,2.94]$ & $1.66(\mathrm{P}=0.10)$ \\
\hline & 2.1.2 CHRONIC & 18 & 412 & $1.21[0.74,1.68]$ & $5.02(\mathrm{P}<0.00001)$ \\
\hline \multirow[t]{3}{*}{5} & Type of memory assessed & $35 *$ & 488 & $1.53[1.04,2.03]$ & $6.11(\mathrm{P}<0.00001)$ \\
\hline & 1.1.1 WORKING & 26 & 298 & $1.74[1.14,2.33]$ & $5.71(\mathrm{P}<0.00001)$ \\
\hline & 1.1.2 RECOGNITION & 9 & 190 & $1.06[0.15,1.97]$ & $2.28(\mathrm{P}=0.02)$ \\
\hline
\end{tabular}

\#-The only study performed with zebra fish was omitted for the sub group analysis

*-All the individual experiments performed to assess the memory from each study were entered for the sub group analys 


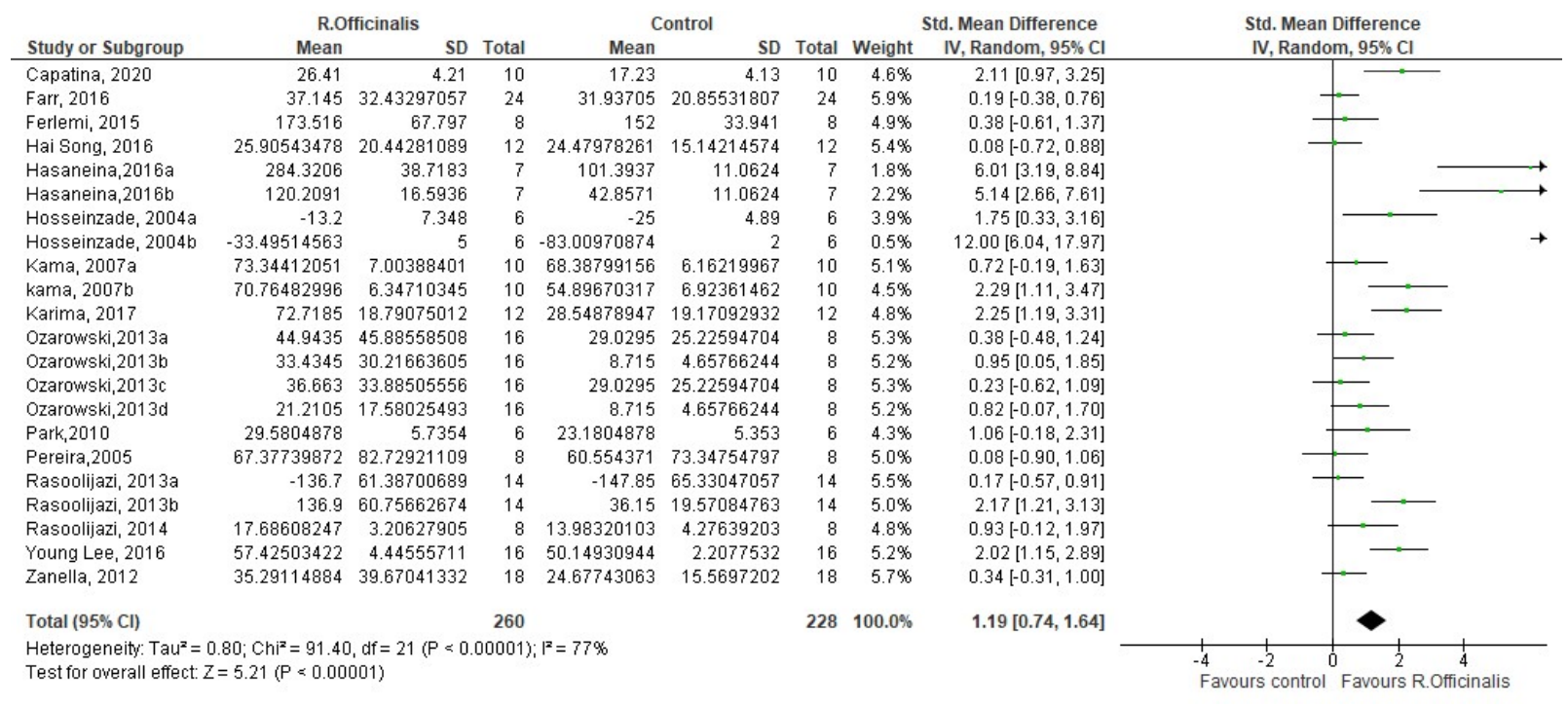

Figure 3 Forest plot of effect of Rosemary officinalis on cognitive performance in lab animals

\begin{tabular}{|c|c|c|c|c|c|c|c|c|c|c|c|}
\hline \multirow[b]{2}{*}{ Study or Subgroup } & \multicolumn{2}{|c|}{ R.officinalis } & \multicolumn{4}{|c|}{ Control } & \multicolumn{2}{|c|}{ Std. Mean Difference } & \multirow{2}{*}{\multicolumn{2}{|c|}{$\begin{array}{l}\text { Std. Mean Difference } \\
\text { IV, Random, } 95 \% \mathrm{Cl}\end{array}$}} & \\
\hline & Mean & SD & Total & Mean & SD & Total & Weight & IV, Random, $95 \% \mathrm{Cl}$ & & & \\
\hline Farr, 2016 & 37.145 & 32.43297057 & 24 & 31.93705 & 20.85531807 & 24 & $12.8 \%$ & $0.19[-0.38,0.76]$ & & 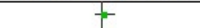 & \\
\hline Ferlemi, 2015 & 173.516 & 67.797 & 8 & 152 & 33.941 & 8 & $8.1 \%$ & $0.38[-0.61,1.37]$ & & - & \\
\hline Hasaneina,2016 & 284.3206 & 38.7183 & 7 & 101.3937 & 11.0624 & 7 & $1.7 \%$ & $6.01[3.19,8.84]$ & & & \\
\hline Hosseinzade, 2004a & -13.2 & 7.348 & 6 & -25 & 4.89 & 6 & $5.2 \%$ & $1.75[0.33,3.16]$ & & $\longrightarrow$ & \\
\hline Kama, 2007 & 73.34412051 & 7.00388401 & 10 & 68.38799156 & 6.16219967 & 10 & $8.9 \%$ & $0.72[-0.19,1.63]$ & & - & \\
\hline Ozarowski,2013a & 44.9435 & 45.88558508 & 16 & 29.0295 & 25.22594704 & 8 & $9.4 \%$ & $0.38[-0.48,1.24]$ & & - & \\
\hline Ozarowski,2013c & 36.663 & 33.88505556 & 16 & 29.0295 & 25.22594704 & 8 & $9.5 \%$ & $0.23[-0.62,1.09]$ & & - & \\
\hline Park, 2010 & 29.5804878 & 5.7354 & 6 & 23.1804878 & 5.353 & 6 & $6.2 \%$ & $1.06[-0.18,2.31]$ & & $\rightarrow$ & \\
\hline Pereira,2005 & 67.37739872 & 82.72921109 & 8 & 60.554371 & 73.34754797 & 8 & $8.2 \%$ & $0.08[-0.90,1.06]$ & & - & \\
\hline Rasoolijazi, 2013a & -136.7 & 61.38700689 & 14 & -147.85 & 65.33047057 & 14 & $10.7 \%$ & $0.17[-0.57,0.91]$ & & - & \\
\hline Rasoolijazi, 2014 & 17.68608247 & 3.20627905 & 8 & 13.98320103 & 4.27639203 & 8 & $7.7 \%$ & $0.93[-0.12,1.97]$ & & 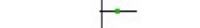 & \\
\hline Zanella, 2012 & 35.29114884 & 39.67041332 & 18 & 24.67743063 & 15.5697202 & 18 & $11.7 \%$ & $0.34[-0.31,1.00]$ & & $=$ & \\
\hline Total $(95 \% \mathrm{Cl})$ & & & 141 & & & 125 & $100.0 \%$ & $0.57[0.19,0.96]$ & & $\bullet$ & \\
\hline $\begin{array}{l}\text { Heterogeneity: Tau }= \\
\text { Test for overall effect: }\end{array}$ & $\begin{array}{l}22 ; \mathrm{Chi}^{2}=22.43 \\
=2.91(\mathrm{P}=0.00\end{array}$ & 3, $d f=11(P=0$ & $02) ; 1^{2}=$ & $=51 \%$ & & & & & -10 & $\begin{array}{ccr}-5 & 0 & 5 \\
\text { burs control } & \text { Favours R. }\end{array}$ & $\begin{array}{r}10 \\
\text { nalis }\end{array}$ \\
\hline
\end{tabular}

Figure 4 Forest plot of effect of R. officinalis on cognitive performance in normal intact animals

\subsection{Stratified analysis}

As the effect estimates in the present study are the outcome of the combination of various subsets of data in individual studies, it was anticipated this might conceal the features or characteristics that can influence the effect size. In this direction, stratified meta-analyses were conducted to investigate the heterogeneity of the data and its impact on the overall estimate in the assessment of the efficacy of the R.O on cognitive improvement in normal intact and cognitively impaired animals. Various subgroups based on study design and participant characteristic such as study animals impaired vs normal intact, species used rat vs mouse, memory assessed reference memory vs recognition, extract used whole extract vs active constituent and duration of treatment, acute vs chronic were defined. Through this we also observed whether the average treatment effect hold true for all types of groups included in the meta-analysis. Subgroup analyses showed a beneficial effect of R.O both for the intact normal rodents as well as impaired rodents (Table 3). The differences between the effect for intact versus impaired animals were statistically significant (intact vs. impaired: $Z=5.21(\mathrm{P}<$ 0.00001). Similar significant effects were observed for the remaining subgroup analyses (rat vs 
mouse, $\mathrm{Z}=4.93(\mathrm{P}<0.00001)$; extract vs active constituent, $\mathrm{Z}=5.21(\mathrm{P}<0.00001)$;reference memory vs recognition memory, $\mathrm{Z}=6.11(\mathrm{P}<0.00001)$ except for the duration of treatment where the overall effect for acute period of treatment was non-significant $(Z=1.66, P=0.10)$ (table 3). However, it may due to the limited number of studies when compared to chronic treatment period (4 vs18).

Table 4 depicts the subgroup analyses for the heterogeneity and group differences by $\left(\mathrm{Chi}^{2}\right.$ and $\left.\mathrm{I}^{2}\right)$ method. The test for subgroup differences suggests that there is a statistically significant subgroup effects in intact vs. impaired $(\mathrm{p}=0.002)$, meaning that condition of animal significantly modifies the effect of R.O treatment in comparison to control. The treatment effect favors R.O over control for both normal intact and intact impaired animals, although the treatment effect is greater for cognitively impaired than normal intact; therefore, the subgroup effect is quantitative. A sufficient number of studies and participants were included in each subgroup, so the covariate distribution is not concerning for this subgroup analysis. However, there is substantial unexplained heterogeneity between the studies within each of these subgroups (Intact normal: $\mathrm{I}^{2}=51 \%$; Intact impaired: $\mathrm{I}^{2}=$ $80 \%$ ). Similarly, heterogeneity study for type of extract of R.O yielded statistically significant subgroup effects in extract vs active constituent $(p=0.005)$. The heterogeneity test for other study characteristics, such as the type of animal species, type of memory assessed and duration of treatment of R.O appeared to have no significant subgroup differences (Table 4).

The subgroup analyses exhibited substantial unexplained heterogeneity between studies within each of these subgroups. Therefore, the validity of the treatment effect estimate for each subgroup is uncertain, as individual results are inconsistent on the benefits of R.O on cognitive performance. So, these tests did not offer any respite in identification of source of heterogeneity (Table 4). Thereby not proving the existence of moderators driving heterogeneity, strongly inviting further investigations for the variability across studies. However limited number of studies and heterogenous comparisons across studies cannot be ruled out in contributing to heterogeneity.

\subsection{Publication bias}

No evident publication bias for the effect of R.O on cognitive performance on normal intact and intact impaired animals (Figure 5) was found through observation of funnel plot. Effect sizes were plotted against SE of the SMD, studies with the largest sample sizes are plotted near the average effect size, and smaller studies are spread evenly on both sides, creating a roughly funnel-shaped distribution. The funnel plot was based on all tasks involving study animals. From the plot two outliers were found.

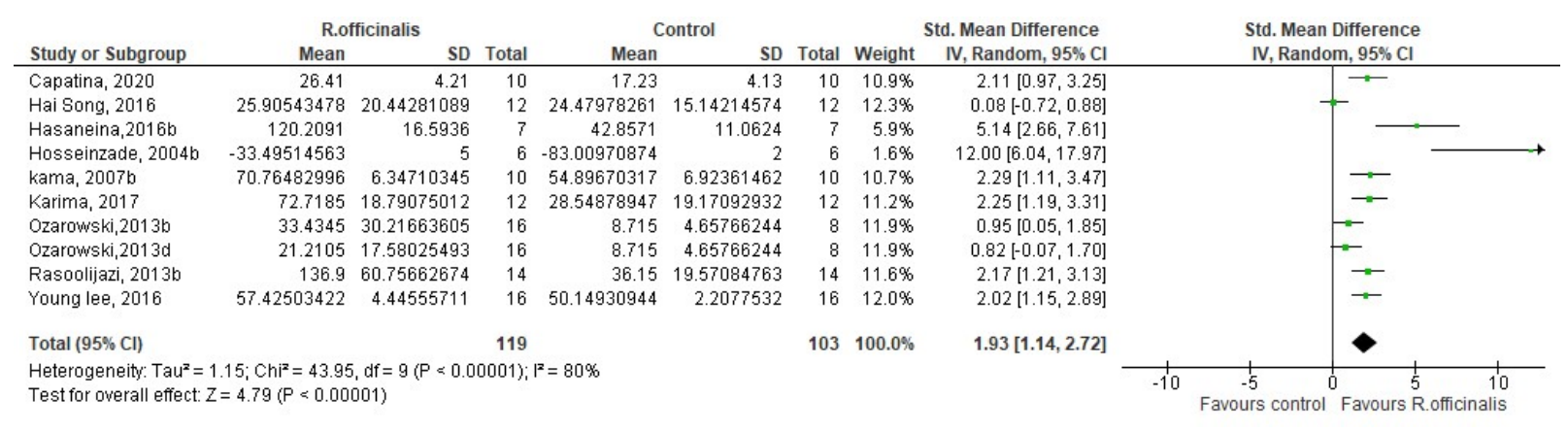

Figure 5: Forest plot of effect of R. officinalis on cognitive performance in intact cognitively impaired animals 


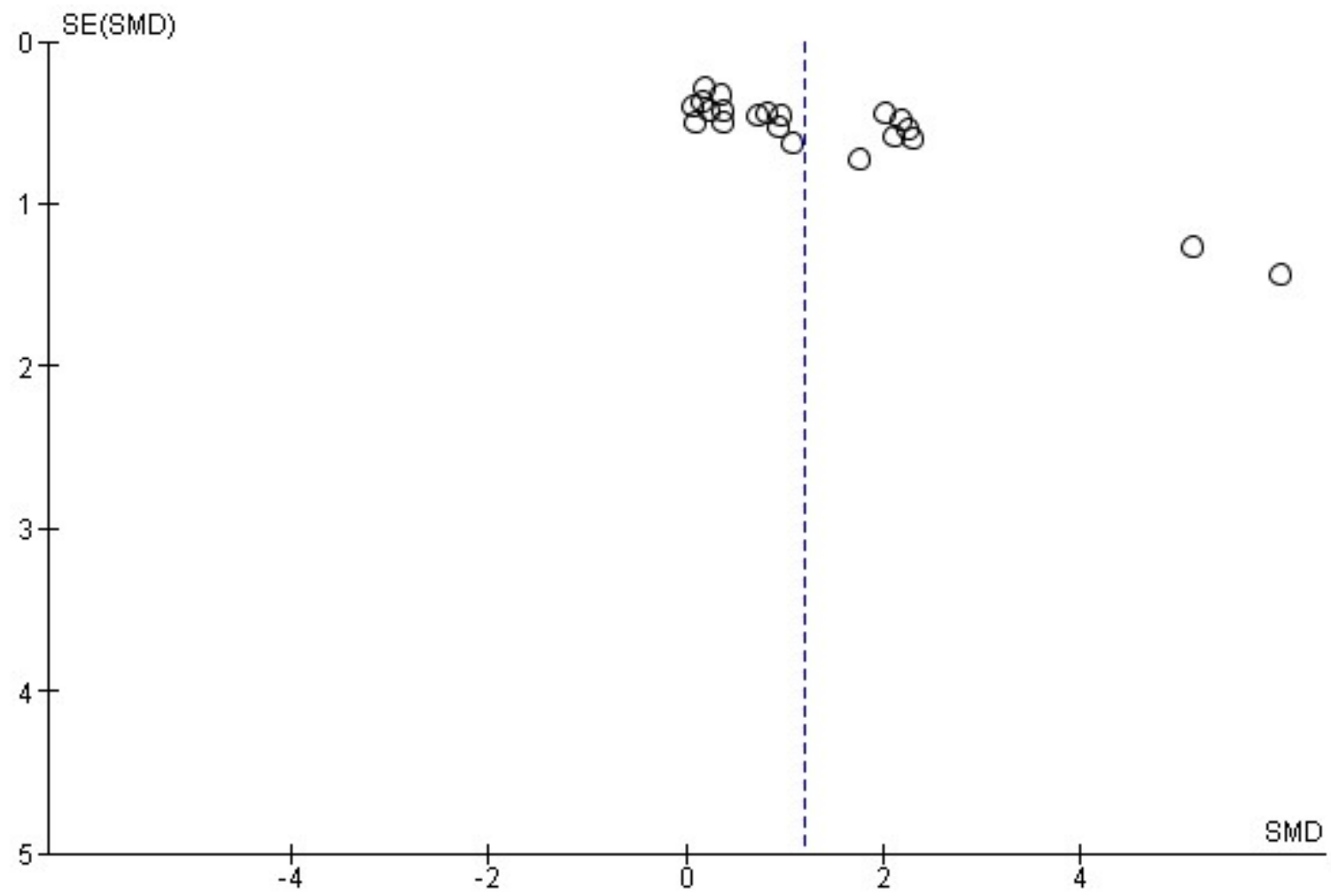

Figure 6: Funnel plot of experimental comparisons on intact rodents (maximal dosages only, different tasks shown separately).

\subsection{Qualitative synthesis of included studies}

The review of published literature on R.O especially for cognitive performance in preclinical studies revealed that a wide variety of animal species were employed in the studies such mice (strains: Swiss male albino, Balb-c mice, ICR mice, SAMP8 mice), rats (strains: Wistar rats, Sprague Dawley rats), fish (wild-type short-fin strain zebrafish). R. O was used in different forms such as extracts of whole plants, leaves, essential oil of the plants, isolated compounds etc. To assess the cognitive enhancing potential of R.O various instruments and tasks were used, active and passive avoidance tests, Morris water maze, Y-Maze, T-Maze, novel object recognition test and social recognition paradigm. Similarly, in vitro tests employed variety of experimental design and cell lines most common were PC12 cells, Cacao cells, T98G human glioblastoma cells. To assess the effect of R.O in cognitive deficit animals, cognitive impairment was induced using various strategies including scopolamine, streptozotocin, amyloid $\beta$, mild injury to brain and genetically modified aging.

The various studies worked on different aspects of learning and memory to assess the effect of R.O and can be concluded with respect to the mechanisms of R.O and its constituents in contributing towards a cognition enhancement as, anticholinesterase, procholinergic, antioxidant, anti-amyloid, neuroprotective and anti-inflammatory agent (Figure 7). 


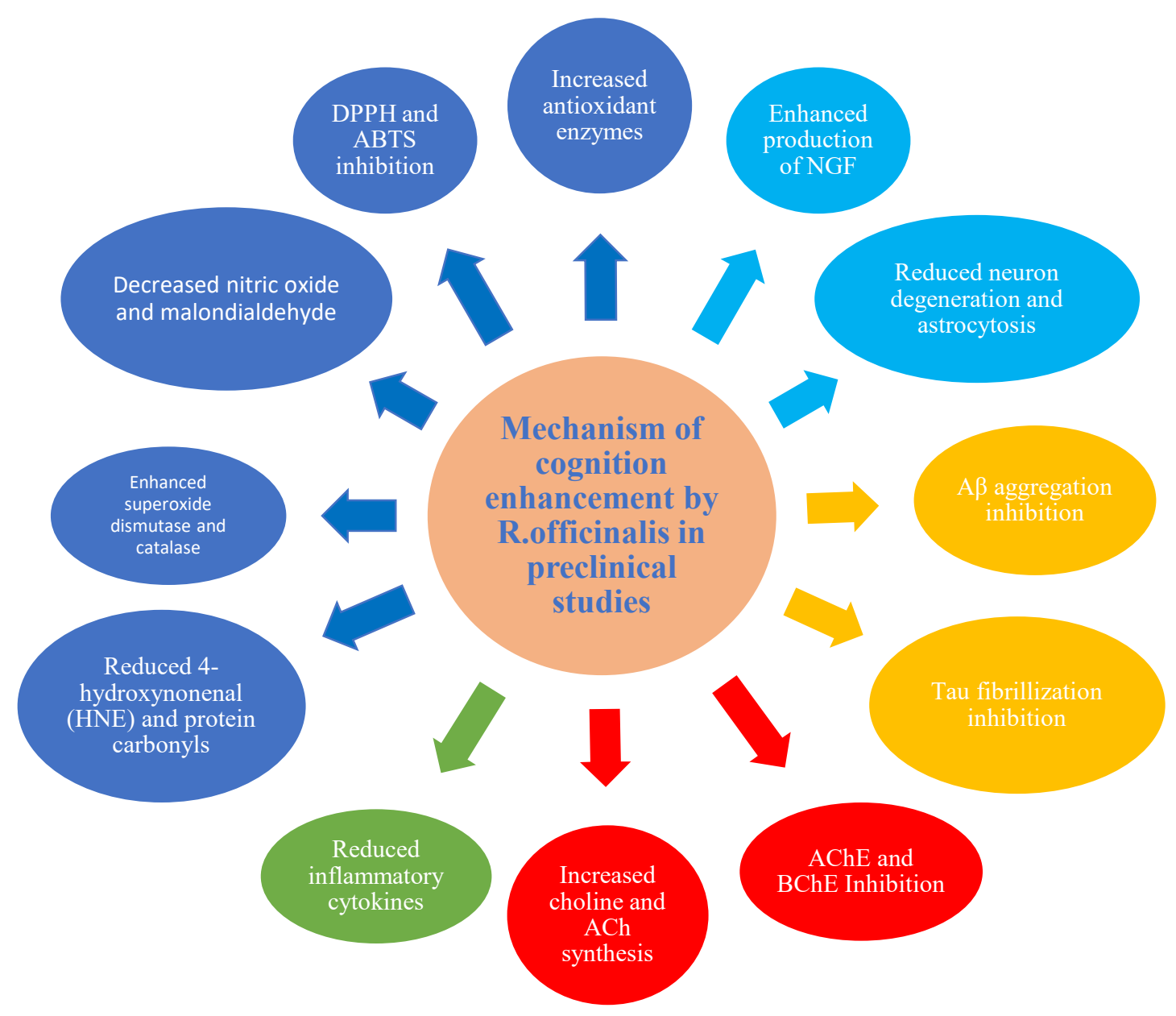

Figure 7: Mechanism of cognition enhancement by R. officinalis in preclinical studies

\section{DISCUSSION}

As the systematic reviews and meta-analyses of animal studies help in gathering evidence for investigating the effects of experimental interventions before proceeding to full-fledged clinical research involving humans, they also pose serious challenges due to variability in the nature of experimental set up, animal species, study characteristics and lab design[51]. The current study is a first to carry systematic review and meta-analysis to examine the efficacy of R.O treatment for improving cognitive activities in animal models assessing memory and learning. Overall, our study suggested that R.O has the ability in improving cognitive outcomes in normal intact as well as impaired intact animals that were robust across species, type of extract, duration and type of memory. The results obtained from across the studies with multiple tasks have been found to improve cognitive function namely in Morris water maze tests R.O and its active constituents treated animals significantly reduced the time of escape latency to reach the target quadrant, and increase the proportion of time spent in the target quadrant; in passive avoidance tasks enhanced stepdown latency to escape aversive stimuli; in novel objection recognition tests have been found to spend comparatively more time investigating the novel object; in T- and Y-Mazes have emerged to cause 
increased alternation movements as an index of improved cognitive performance following treatment with R.O. This forms the basis of considerable amount of heterogeneity observed across studies where the subgroup analyses failed to find any moderator role in the heterogeneity.

A meta-analytic study of R.O revealed that it has large nootropic effects in the preclinical tests, though it was clear in the individual studies, the effect was more prominent in study animals with impaired cognitive performance when compared to normal intact animals.

Though these tests belong to varied classes of tasks designed to assess particular component of memory or learning process, for the sake of present study they were broadly categorized into two types, one that assess reference memory and another recognition memory[52][53], [54]. All the experiments performed with Morris water maze, active/passive avoidance paradigms and T-and YMazes were classed as assessing reference memory. The novel recognition tests and social recognition paradigms as assessing recognition memory. Interestingly, the cognition enhancing effect was observed in tasks involving both the characteristics of memory as described above. This implies that the effect of R.O on performance is mediated by influencing broader learning and memory processes in the body of treated animals. It is also noteworthy, that effect of R.O was stronger in cognitively impaired animals as compared to normal intact ones. These findings demand further enquiry into the mechanistic and pharmacological characteristics of R.O in elucidating the effect on cognitive performance. Finally, qualitative synthesis saw varied pharmacological effects of R.O and its active constituents in different models and experiments across studies. The mechanisms of action in exerting a nootropic effect also varied across studies as essential oil of RO produced notable inhibitions of both $\mathrm{AChE}$ and $\mathrm{BuChE}$ enzymes and also restored the scopolamine induced AChE alteration in brain [39], [40], [45]. Carnosic acid was found to enhance production of NGF, total choline level and ACh leading to attenuated cholinergic neurons atrophy. It also reduced the degeneration of hippocampal neurons against $A \beta$, reduced age-related brain tissue markers of oxidation and increased the activity of antioxidant enzymes[28],[49]. Similarly, RA-also found to improve total choline level and ACh synthesis leading to attenuated cholinergic neurons atrophy and inhibited AChE activity. RA significantly also decreased the levels of nitric oxide (NO), malondialdehyde (MDA) and prolyl oligopeptidase (POP) and enhanced antioxidant enzymes, superoxide dismutase and catalase without showing DNA damage in any parameters of brain damage. Finally, RA produced inhibition of $A \beta$ aggregation by increasing concentration of monoamine including DA and inhibited tau fibrillization and prevention of $A \beta$-sheet assembly[32][48]49[55]. Nepitrin also showed anticholinesterase and antioxidant activities and in additional molecular docking studies, nepitrin occupied the same binding site and was found to form similar interactions to those formed by donepezil (Anti-AChE agent) in the crystal structure of AChE, thereby confirming its AChE inhibitory activity[25]. To conclude the multifaceted mechanisms of action of R.O and its constituents, it may be safely stated that R.O and its associated chemical constituents contribute a cocktail of anticholinesterase, procholinergic, antioxidant, antiamyloid, neuroprotective and anti-inflammatory mechanisms in contributing towards a cognition enhancement(Figure 7)[12]22[56].

Apart from the evidences from preclinical evidences, it is also noteworthy to mention here the various clinical studies on the effects of R.O on different aspects of memory such as pengelly et al. reported the effects of R.O in elderly population where R.O produced an increase in the speed of memory[57]. Also, Perry et al. found that a combination of sage, R.O, and lemon balm had significant effects on the improvement of verbal episodic memory in healthy people under 63 years of age[58] . Contrary to this Lindheimer et al. found no significant improvements to perform 
cognitive tasks in young adults with low energy[59]. Pouya Nematolahi reported in university students that R.O could boost prospective and retrospective memory, reduce anxiety and depression, and improve sleep quality[60]. Mark Moss and Lorraine Olive studied reported a correlation between plasma 1,8-cineole levels following aromatherapy with R.O and cognitive performance. AN increase in 1,8-cineole level increased cognitive performance[61]. Thitikul Raetong et al assessed the efficacy of aromatherapy with essential oil of R.o on cognition and BPSD symptoms in patients with mild cognitive impairment and found that aromatherapy to be safe and effective for improving cognitive and behavioral problems in patients with MCI[62].

\section{Limitations of study}

There are some limitations in our study. Firstly, animal model of cognitive deficit does not fully represent aspects of human cognitive function thereby limiting the translation of results to a clinical population. Secondly, potential publication bias is likely to exist although we had made an extensive effort to identify all the relevant studies, our analysis was only able to include data from the published studies in this field. Our analysis did not take unpublished data into account, so our study might overestimate the overall effect size. During stratified meta-analysis, subgroup analyses failed to find out the moderators accounting for considerable heterogeneity between studies.

\section{Clinical implications}

The use of R.O and its active constituents appear to have the potential to reduce cognitive deficit and improve performance in the learning and memory. Use of R.O is safe and has the greatest potential for clinical practice. Though the clinical trials on use of R.O did report its beneficial effects, however, more robust and objective trials need to be conducted. The current review and quantitative synthesis should offer the required information about R.O and help to guide future clinical trials and clinical decisions.

\section{CONCLUSIONS}

Our present systematic review with meta-analysis indicates that administration of R.O improves cognitive function in animal models of cognitive deficit as well as normal intact animals. These results suggest the outcomes may be translated to clinical study provided the studies are robust enough to account for the heterogeneity observed. The cognitive benefits provided by RO and their mechanisms of action are in sync with the fundamental pathophysiology of the cognitive deficit and hence can offer great source remedies for treatment of Alzheimer's disease. 


\section{References}

[1] A. C. Tricco et al., "Efficacy and safety of cognitive enhancers for patients with mild cognitive impairment: A systematic review and meta-analysis," Cmaj, vol. 185, no. 16, pp. 1393-1401, 2013, doi: 10.1503/cmaj.130451.

[2] G. Z. Steiner et al., "A systematic review of intervention studies examining nutritional and herbal therapies for mild cognitive impairment and dementia using neuroimaging methods: Study characteristics and intervention efficacy," Evidence-based Complement. Altern. Med., vol. 2017, 2017, doi: 10.1155/2017/6083629.

[3] D. P.A., M. R.S., G. M., L. J.D., and F. J., “Alzheimer's disease clinical and research update for health care practitioners," J. Aging Res., vol. 2013, no. Mci, 2013.

[4] Y. Niu, D. Ye, Y. You, and J. Wu, "Prophylactic cognitive enhancers for improvement of cognitive function in patients undergoing electroconvulsive therapy: A systematic review and meta-analysis," Medicine (Baltimore)., vol. 99, no. 11, p. e19527, 2020, doi: 10.1097/MD.0000000000019527.

[5] M. Mazza, A. Capuano, P. Bria, and S. Mazza, "Ginkgo biloba and donepezil: A comparison in the treatment of Alzheimer's dementia in a randomized placebo-controlled double-blind study," Eur. J. Neurol., vol. 13, no. 9, pp. 981-985, Sep. 2006, doi: 10.1111/j.1468-1331.2006.01409.x.

[6] A. R. Desilets, J. J. Gickas, and K. C. Dunican, "Role of huperzine a in the treatment of Alzheimer's disease.," Ann. Pharmacother., vol. 43, no. 3, pp. 514-8, Mar. 2009, doi: 10.1345/aph.1L402.

[7] J. H. Heo et al., "An open-label trial of Korean red ginseng as an adjuvant treatment for cognitive impairment in patients with Alzheimer's disease," Eur. J. Neurol., vol. 15, no. 8, pp. 865-868, Aug. 2008, doi: 10.1111/j.1468-1331.2008.02157.x.

[8] S.-T. Lee, K. Chu, J.-Y. Sim, J.-H. Heo, and M. Kim, "Panax ginseng enhances cognitive performance in Alzheimer disease.," Alzheimer Dis. Assoc. Disord., vol. 22, no. 3, pp. 2226, Jul. 2008, doi: 10.1097/WAD.0b013e31816c92e6.

[9] K. Maurer, R. Ihl, T. Dierks, and L. Frölich, "Clinical efficacy of Ginkgo biloba special extract EGb 761 in dementia of the Alzheimer type," J. Psychiatr. Res., vol. 31, no. 6, pp. 645-655, 1997, doi: 10.1016/S0022-3956(97)00022-8.

[10] K. Maurer, R. Ihl, T. Dierks, and L. Frölich, "Clinical efficacy of Ginkgo biloba special extract EGb 761 in dementia of the Alzheimer type.," Phytomedicine, vol. 5, no. 6, pp. 41724, Dec. 1998, doi: 10.1016/S0944-7113(98)80037-8.

[11] D. Kennedy and A. Scholey, "The Psychopharmacology of European Herbs with CognitionEnhancing Properties," Curr. Pharm. Des., vol. 12, no. 35, pp. 4613-4623, Dec. 2006, doi: 10.2174/138161206779010387.

[12] H. S, "The Therapeutic Potential of Rosemary (Rosmarinus officinalis) Diterpenes for Alzheimer's Disease,” Evid. Based. Complement. Alternat. Med., vol. 2016, 2016, doi: $10.1155 / 2016 / 2680409$. 
[13] J. Yamamoto, K. Yamada, A. Naemura, T. Yamashita, and R. Arai, "Testing various herbs for antithrombotic effect," Nutrition, vol. 21, no. 5, pp. 580-587, May 2005, doi: 10.1016/j.nut.2004.09.016.

[14] M. Estévez, R. Ramírez, S. Ventanas, and R. Cava, "Sage and rosemary essential oils versus BHT for the inhibition of lipid oxidative reactions in liver pâté," LWT - Food Sci. Technol., vol. 40, no. 1, pp. 58-65, Jan. 2007, doi: 10.1016/j.lwt.2005.07.010.

[15] G. A. N. de Melo et al., "Rosmarinus officinalis L. Essential Oil Inhibits In Vivo and In Vitro Leukocyte Migration," J. Med. Food, vol. 14, no. 9, pp. 944-946, Sep. 2011, doi: 10.1089/jmf.2010.0159.

[16] M. E. González-Trujano et al., "Evaluation of the antinociceptive effect of Rosmarinus officinalis L. using three different experimental models in rodents," J. Ethnopharmacol., vol. 111, no. 3, pp. 476-482, May 2007, doi: 10.1016/j.jep.2006.12.011.

[17] T. Bakirel, U. Bakirel, O. Ü. Keleş, S. G. Ülgen, and H. Yardibi, "In vivo assessment of antidiabetic and antioxidant activities of rosemary (Rosmarinus officinalis) in alloxandiabetic rabbits," J. Ethnopharmacol., vol. 116, no. 1, pp. 64-73, Feb. 2008, doi: 10.1016/j.jep.2007.10.039.

[18] O. Yesil-Celiktas, C. Sevimli, E. Bedir, and F. Vardar-Sukan, "Inhibitory effects of rosemary extracts, carnosic acid and rosmarinic acid on the growth of various human cancer cell lines," Plant Foods Hum. Nutr., vol. 65, no. 2, pp. 158-163, 2010, doi: 10.1007/s11130-010-0166-4.

[19] A. Allegra, A. Tonacci, G. Pioggia, C. Musolino, and S. Gangemi, "Anticancer activity of rosmarinus officinalis L.: Mechanisms of action and therapeutic potentials," Nutrients, vol. 12, no. 6. MDPI AG, pp. 1-25, 01-Jun-2020, doi: 10.3390/nu12061739.

[20] B. Bozin, N. Mimica-Dukic, I. Samojlik, and E. Jovin, “Antimicrobial and antioxidant properties of Rosemary and Sage (Rosmarinus officinalis L. and Salvia officinalis L., Lamiaceae) essential oils," J. Agric. Food Chem., vol. 55, no. 19, pp. 7879-7885, Sep. 2007, doi: 10.1021/jf0715323.

[21] L. Gachkar, D. Yadegari, M. B. Rezaei, M. Taghizadeh, S. A. Astaneh, and I. Rasooli, "Chemical and biological characteristics of Cuminum cyminum and Rosmarinus officinalis essential oils," Food Chem., vol. 102, no. 3, pp. 898-904, Jan. 2007, doi: 10.1016/j.foodchem.2006.06.035.

[22] C. Ulbricht et al., "An evidence-based systematic review of rosemary (Rosmarinus officinalis) by the Natural Standard Research Collaboration," J. Diet. Suppl., vol. 7, no. 4, pp. 351-413, 2010, doi: 10.3109/19390211.2010.525049.

[23] M. R. Al-Sereiti, K. M. Abu-Amer, and P. Sen, "Pharmacology of rosemary (Rosmarinus officinalis Linn.) and its therapeutic potentials," Indian Journal of Experimental Biology, vol. 37, no. 2. National Institute of Science Communication, pp. 124-130, 1999.

[24] I. Borrás-Linares et al., "Rosmarinus officinalis leaves as a natural source of bioactive compounds," Int. J. Mol. Sci., vol. 15, no. 11, pp. 20585-20606, Sep. 2014, doi: 10.3390/ijms 151120585 . 
[25] N. Karim, I. Khan, A. Abdelhalim, H. Abdel-Halim, and J. R. Hanrahan, "Molecular docking and antiamnesic effects of nepitrin isolated from Rosmarinus officinalis on scopolamine-induced memory impairment in mice," Biomed. Pharmacother., vol. 96, no. September, pp. 700-709, 2017, doi: 10.1016/j.biopha.2017.09.121.

[26] S. Birtić, P. Dussort, F. X. Pierre, A. C. Bily, and M. Roller, "Carnosic acid," Phytochemistry, vol. 115, no. 1. Elsevier Ltd, pp. 9-19, 2015, doi: 10.1016/j.phytochem.2014.12.026.

[27] M. Alagawany et al., "Rosmarinic acid: Modes of action, medicinal values and health benefits," Animal Health Research Reviews, vol. 18, no. 2. Cambridge University Press, pp. 167-176, 01-Dec-2017, doi: 10.1017/S1466252317000081.

[28] K. Kosaka and T. Yokoi, "Carnosic acid, a component of rosemary (Rosmarinus officinalis L.), promotes synthesis of nerve growth factor in T98g human glioblastoma cells," Biol. Pharm. Bull., vol. 26, no. 11, pp. 1620-1622, 2003, doi: 10.1248/bpb.26.1620.

[29] P. Pereira, D. Tysca, P. Oliveira, L. F. D. S. Brum, J. N. Picada, and P. Ardenghi, "Neurobehavioral and genotoxic aspects of rosmarinic acid," Pharmacol. Res., vol. 52, no. 3, pp. 199-203, 2005, doi: 10.1016/j.phrs.2005.03.003.

[30] "WebPlotDigitizer - Extract data from plots, images, and maps." [Online]. Available: https://automeris.io/WebPlotDigitizer/. [Accessed: 28-Jul-2020].

[31] "RevMan for non-Cochrane reviews | Cochrane Training." [Online]. Available: https://raining.cochrane.org/online-learning/core-software-cochranereviews/revman/revman-non-cochrane-reviews. [Accessed: 28-Jul-2020].

[32] M. Ozarowski et al., "Rosmarinus officinalis L. leaf extract improves memory impairment and affects acetylcholinesterase and butyrylcholinesterase activities in rat brain," Fitoterapia, vol. 91, pp. 261-271, 2013, doi: 10.1016/j.fitote.2013.09.012.

[33] H. Song et al., "Rosemary extract improves cognitive deficits in a rats model of repetitive mild traumatic brain injury associated with reduction of astrocytosis and neuronal degeneration in hippocampus," Neurosci. Lett., vol. 622, pp. 95-101, 2016, doi: 10.1016/j.neulet.2016.04.048.

[34] A. V. Ferlemi et al., "Rosemary tea consumption results to anxiolytic- and anti-depressantlike behavior of adult male mice and inhibits all cerebral area and liver cholinesterase activity; Phytochemical investigation and in silico studies," Chem. Biol. Interact., vol. 237, pp. 47-57, 2015, doi: 10.1016/j.cbi.2015.04.013.

[35] C. A. Zanella, H. Treichel, R. L. Cansian, and S. S. Roman, "The effects of acute administration of the hydroalcoholic extract of rosemary (Rosmarinus officinalis L.) (Lamiaceae) in animal models of memory," Brazilian J. Pharm. Sci., vol. 48, no. 3, pp. 389-397, 2012, doi: 10.1590/S1984-82502012000300005.

[36] H. Rasoolijazi, M. Mehdizadeh, M. Soleimani, F. Nikbakhte, M. E. Farsani, and S. Ababzadeh, "The effect of rosemary extract on spatial memory, learning and antioxidant enzymes activities in the hippocampus of middle-aged rats," Med. J. Islam. Repub. Iran, vol. 29, 2015. 
[37] S. A. Farr et al., "Effect of botanical extracts containing carnosic acid or rosmarinic acid on learning and memory in SAMP8 mice," Physiol. Behav., vol. 165, pp. 328-338, 2016, doi: 10.1016/j.physbeh.2016.08.013.

[38] H. Rasoolijazi, N. Azad, M. T. Joghataei, M. Kerdari, F. Nikbakht, and M. Soleimani, "The protective role of carnosic acid against beta-amyloid toxicity in rats," Sci. World J., vol. 2013, 2013, doi: 10.1155/2013/917082.

[39] H. Hosseinzadeh, G. Karimi, and Nobakht, "Effects of Rosmarinus officinalis L. aerial parts essential oil on intact memory and scopolamine-induced learning deficits in rats performing the Morris water maze task," J. Med. Plants, vol. 3, no. 12, pp. 51-57, 2004.

[40] L. Capatina et al., "Rosmarinus officinalis essential oil improves scopolamine-induced neurobehavioral changes via restoration of cholinergic function and brain antioxidant status in Zebrafish (Danio rerio)," Antioxidants, vol. 9, no. 1, 2020, doi: 10.3390/antiox9010062.

[41] A. Y. Lee, B. R. Hwang, M. H. Lee, S. Lee, and E. J. Cho, "Perilla frutescens var. japonica and rosmarinic acid improve amyloid- $\beta 25-35$ induced impairment of cognition and memory function," Nutr. Res. Pract., vol. 10, no. 3, pp. 274-281, 2016, doi:

10.4162/nrp.2016.10.3.274.

[42] P. Hasanein, Z. Felehgari, and A. Emamjomeh, "Preventive effects of Salvia officinalis L. against learning and memory deficit induced by diabetes in rats: Possible hypoglycaemic and antioxidant mechanisms," Neurosci. Lett., vol. 622, pp. 72-77, 2016, doi:

10.1016/j.neulet.2016.04.045.

[43] T. Alkam, A. Nitta, H. Mizoguchi, A. Itoh, and T. Nabeshima, "A natural scavenger of peroxynitrites, rosmarinic acid, protects against impairment of memory induced by A $\beta 25$ 35," Behav. Brain Res., vol. 180, no. 2, pp. 139-145, 2007, doi: 10.1016/j.bbr.2007.03.001.

[44] A. Depeursinge et al., "Fusing Visual and Clinical Information for Lung Tissue Classification in HRCT Data," Artif. Intell. Med., vol. 81, p. 1118, 2010, doi: 10.1016/j.

[45] I. Orhan, S. Aslan, M. Kartal, B. Şener, and K. Hüsnü Can Başer, "Inhibitory effect of Turkish Rosmarinus officinalis L. on acetylcholinesterase and butyrylcholinesterase enzymes," Food Chem., vol. 108, no. 2, pp. 663-668, 2008, doi: 10.1016/j.foodchem.2007.11.023.

[46] S. Vladimir-Knezevic, B. Blazekovic, M. Kindl, J. Vladic, A. D. Lower-Nedza, and A. H. Brantner, "Acetylcholinesterase inhibitory, antioxidant and phytochemical properties of selected medicinal plants of the lamiaceae family," Molecules, vol. 19, no. 1, pp. 767-782, 2014, doi: 10.3390/molecules 19010767.

[47] T. Hase et al., "Rosmarinic acid suppresses Alzheimer's disease development by reducing amyloid $\beta$ aggregation by increasing monoamine secretion," Sci. Rep., vol. 9, no. 1, pp. 113, 2019, doi: 10.1038/s41598-019-45168-1.

[48] A. Cornejo et al., "Rosmarinic acid prevents fibrillization and diminishes vibrational modes associated to $\beta$ sheet in tau protein linked to Alzheimer's disease," J. Enzyme Inhib. Med. Chem., vol. 32, no. 1, pp. 945-953, Jan. 2017, doi: 10.1080/14756366.2017.1347783.

[49] A. El Omri, J. Han, P. Yamada, K. Kawada, M. Ben Abdrabbah, and H. Isoda, "Rosmarinus 
officinalis polyphenols activate cholinergic activities in PC12 cells through phosphorylation of ERK1/2," J. Ethnopharmacol., vol. 131, no. 2, pp. 451-458, 2010, doi:

10.1016/j.jep.2010.07.006.

[50] S. O. Emmanuel and M. Tahan, “Accepted Manuscript Accepted Manuscript ( Uncorrected Proof )," pp. 1-19, 2019.

[51] H. M. Vesterinen et al., "Meta-analysis of data from animal studies: A practical guide," $J$. Neurosci. Methods, vol. 221, pp. 92-102, 2014, doi: 10.1016/j.jneumeth.2013.09.010.

[52] D. Ben-Eliezer and E. Yechiam, "Hypericum perforatum as a cognitive enhancer in rodents: A meta-analysis,” Sci. Rep., vol. 6, no. September, pp. 1-9, 2016, doi: 10.1038/srep35700.

[53] P. A. Dudchenko, "An overview of the tasks used to test working memory in rodents," Neurosci. Biobehav. Rev., vol. 28, no. 7, pp. 699-709, 2004, doi:

10.1016/j.neubiorev.2004.09.002.

[54] B. Lian, J. Gao, N. Sui, T. Feng, and M. Li, "Object, spatial and social recognition testing in a single test paradigm," Neurobiol. Learn. Mem., vol. 152, no. February, pp. 39-49, 2018, doi: 10.1016/j.nlm.2018.05.006.

[55] P. Gürbüz, A. Martinez, C. Pérez, L. Martínez-González, F. Göger, and İ. Ayran, "Potential anti-Alzheimer effects of selected Lamiaceae plants through polypharmacology on glycogen synthase kinase-3 $\beta, \beta$-secretase, and casein kinase $1 \delta$," Ind. Crops Prod., vol. 138, no. December 2018, 2019, doi: 10.1016/j.indcrop.2019.05.080.

[56] R. Inatani, N. Nakatani, and H. Fuwa, "Antioxidative Effect of the Constituents of Rosemary (Rosmarinus officinalis L.) and Their Derivatives," Agric. Biol. Chem., vol. 47, no. 3, pp. 521-528, 1983, doi: 10.1271/bbb1961.47.521.

[57] A. Pengelly, J. Snow, S. Y. Mills, A. Scholey, K. Wesnes, and L. R. Butler, "Short-term study on the effects of rosemary on cognitive function in an elderly population," J. Med. Food, vol. 15, no. 1, pp. 10-17, Jan. 2012, doi: 10.1089/jmf.2011.0005.

[58] N. S. L. Perry et al., "A randomised double-blind placebo-controlled pilot trial of a combined extract of sage, rosemary and melissa, traditional herbal medicines, on the enhancement of memory in normal healthy subjects, including influence of age," Phytomedicine, vol. 39, pp. 42-48, Jan. 2018, doi: 10.1016/j.phymed.2017.08.015.

[59] J. B. Lindheimer, B. D. Loy, and P. J. O’Connor, "Short-term effects of black pepper (piper nigrum) and rosemary (rosmarinus officinalis and rosmarinus eriocalyx) on sustained attention and on energy and fatigue mood states in young adults with low energy," $J$. Med. Food, vol. 16, no. 8, pp. 765-771, Aug. 2013, doi: 10.1089/jmf.2012.0216.

[60] P. Nematolahi, M. Mehrabani, S. Karami-Mohajeri, and F. Dabaghzadeh, "Effects of Rosmarinus officinalis L. on memory performance, anxiety, depression, and sleep quality in university students: A randomized clinical trial," Complement. Ther. Clin. Pract., vol. 30, pp. 24-28, 2018, doi: 10.1016/j.ctcp.2017.11.004.

[61] M. Moss and L. Oliver, "Plasma 1,8-cineole correlates with cognitive performance following exposure to rosemary essential oil aroma," Ther. Adv. Psychopharmacol., vol. 2, no. 3, pp. 103-113, 2012, doi: 10.1177/2045125312436573. 
[62] T. Raetong, T. Tantirittisak, and R. Chaiteerakij, "Effect of Aromatherapy on Patient with Mild Cognitive Impairment in Prasat Neurological," vol. 35, no. 1, pp. 27-34, 2019. 